\title{
Influence of Specimen Thicknesson Cracking Behaviorin Restrained Shrinkage Ring Test
}

\author{
W. Dong, X. M. Zhou, and Z. M. Wu
}

\begin{abstract}
The standard test method using circular ring is adopted to assess the potential cracking of restrained shrinkage concrete by ASTM and AASHTO, respectively. The difference of them is the ring specimen thickness, which are $37.5 \mathrm{~mm}$ and $75 \mathrm{~mm}$. To investigate the mechanism of ring tests with two concrete thicknesses, a numerical approach is proposed to simulate stress development and crack initiation in restrained concrete ring subject to circumferential drying.Afictitious temperature field is applied on concrete ring to simulate the mechanical effect of shrinkage of concrete. Cracking age and position of those concrete ring specimens are obtained from numerical analyses which agree reasonably well with experimental results. It is found that thin and thick ring specimens exhibit different cracking behavior, and the specimen thickness influences the cracking age, position and propagated direction.
\end{abstract}

Index Terms-Concrete, restrained shrinkage, cracking, ring test

\section{INTRODUCTION}

Shrinkage cracking of early-age concrete occurs when tensile stress generated due to restrained volume contraction of concrete exceeds its tensile strength, which is a major problem for flat concrete elements/structures with large exposed surface area-to-volume ratio (A/V), such as industrial floors, concrete pavements and bridge decks. The potential for early-age cracking is influenced by the magnitude of shrinkage, restrained degree of concrete element, age-dependent material properties and structural geometry. Cracking tendency of concrete has been mainly evaluated under restrained conditions by qualitative means through a variety of cracking tests, such as the bar, the plate/slab and the ring tests, among which the circular ring test has been widely used for assessing cracking tendency of mortar and concrete due to its simplicity and versatility [1], [2].

As a standard test method for assessing cracking potential of concrete and other cement-based materials, circular ring test is first approved by American Association of State Highway and Transportation (AASHTO), i.e. AASHTO

Manuscript received May 15, 2013; revised July 5, 2013. This work was supported by the Engineering and Physical Sciences Research Council under the grant of EP/I031952/1 and the National Natural Science Foundation of China under the grant NSFC51109026.

W. Dong and Z. M. Wu is with the State Key Laboratory of Coastal and Offshore Engineering,Dalian University of Technology, Dalian 116024, China (e-mail: dongwei@dlut.edu.cn, Zhiminwu2002@yahoo.com.cn).

X. M. Zhou is with the School of Engineering and Design, Brunel University, London, UB8 3PH, UK (e-mail: Xiangming.Zhou@brunel.ac.uk).
PP34-99: standard practice for cracking tendency using a ring specimen, which consists of a concrete ring with an inner diameter of $305 \mathrm{~mm}$, and a wall thickness and height of 75 $\mathrm{mm}$ and $150 \mathrm{~mm}$, respectively, with the restraining core of a steel ring with a wall thickness of $12.5 \mathrm{~mm}$. Later, circular ring test is also adopted by ASTM (ASTM C1581/C1581M-09a: standard test method for determining age at cracking and induced tensile stress characteristics of mortar and concrete under restrained shrinkage) to quantify different mixtures propensity of cracking. Different from AASHTO, ASTM recommends thin rings with a reduced wall thickness of $37.5 \mathrm{~mm}$ to enable cracking to initiate at an earlier age to shorten the duration of ring test.

It is believed that the thickness of concrete ring wall has a significant effect on the stress development in concrete under restrained shrinkage. Experiments have indicated that thicker sections exhibited higher resistance to cracking than thinner ones, which suggests that age of cracking of concrete is different in structures with different thickness [3].Experiment indicated that crack initiates at the outer circumference and propagates toward to the inner circumference of a thick ring when drying from its outer circumferential surface in restrained shrinkage test [4].The crack initial position was attributed to the influence of drying condition in the test, i.e. drying from top and bottom, or from the outer circumference. While, it was considered that crack would initiate at the inner circumference of a thin ring and propagate toward the outer surface when drying from its outer circumferential surface [5].Therefore, the influence of specimen thickness on the crack initial position should be taken into account in the analysis of cracking behavior for the restrained shrinkage test drying from outer circumference.

In line with this, a numerical approach is developed in this study to simulate the shrinkage behavior of different thicknesses concrete in restrained ring specimens drying from the outer circumference. A fictitious temperature field was applied on concrete ring specimens in numerical analyses to simulate the mechanical effect of concrete shrinkage on rings under restrained condition. The fictitious temperature field is derived based on free shrinkage test of concrete prisms by considering that the free shrinkage strain of the prisms is caused by the fictitious temperature field applied on them which leads to the same value of contraction as shrinkage does. The stress developmentis analyzed to predict cracking age and position in both thin and thick concrete ring specimens subject to restrained shrinkage. It is expected that the experimental and numerical investigations presented here will help to better understand how the ring test works, stress development and crack initiation/propagation in restrained concrete rings under outer circumferential drying. 


\section{EXPERIMENTAL PROGRAM}

The mix proportion for the concrete used for this study was 1:1.5:1.5:0.5 (cement: sand: coarse aggregate: water) by weight, and the maximum of aggregate size was $10 \mathrm{~mm}$.

\section{A. Materials Properties}

Mechanical properties of concrete, elastic modulus $E$, splitting tensile strength $f_{\mathrm{t}}$ and uniaxial compressive strength $f_{\mathrm{c}}$, at different ages were measured using $100 \mathrm{~mm}$ diameter and 200 length cylindrical specimens in this study. After curing in sealed cylindrical moulds in normal laboratory environment for $24 \mathrm{~h}$, the specimens were de-moulded and moved into an environment chamber with $23^{\circ} \mathrm{C}$ and $50 \%$ relative humidity $(\mathrm{RH})$ for curing till the desirable ages of testing.

Regression analyses were conducted on the experimental data to obtain continuous functions that can represent the age-dependent mechanical properties, in this case, $E$ and $f_{t}$, for the concrete. It was found that elastic modulus, $E$, of the concrete at early ages can be predicted using Equation 1.

$$
E(\mathrm{t})=0.0002 \mathrm{t}^{3}-0.0134 t^{2}+0.3693 t+12.715 \quad(t \leq 28)(1)
$$

Splitting tensile strength, $f_{t}$, can be predicted using Equation 2.

$$
f_{t}(t)=1.82 t^{0.13}(t \leq 28)
$$

In both equations, $t$ is the age (unit: day) of concrete. The values of $E$ and $f_{t}$ for concrete at other ages which were not directly measured can be obtained from Eq. (1) and (2).

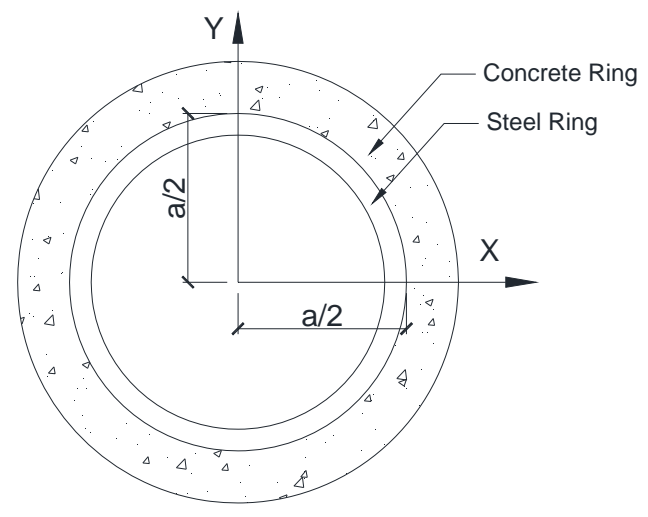

Fig. 1. Notation of geometrical parameters of ring specimens

\section{B. Free Shrinkage Tests}

Free shrinkage was measured on concrete prisms with the dimensions of $280 \mathrm{~mm}$ in length and $75 \mathrm{~mm}$ square in cross section, conforming to ISO 1920-8, subject to drying in the same environment chamber as for curing concrete cylinders. Their longitudinal length change was monitored by a dial gauge, which was then converted into shrinkage. Considering that concrete shrinkage depends on the value of $\mathrm{A} / \mathrm{V}$, four different exposure conditions, i.e. four different values of $\mathrm{A} / \mathrm{V}$, were investigated, i.e. all surfaces sealed, all surface exposed, two side surfaces sealed and three side surfaces sealed, respectively. In experiment, double-layer aluminum tape was used to seal the desired surfaces which were not intended for drying. Initial measurement was carried out immediately after the concrete prisms were de-molded at the age of 1 day and the measurements were continuously recorded twice per day until 28 days.

\section{Restrained Ring Tests}

As aforementioned, the restrained ring test has been widely used to assess the potential for shrinkage cracking in concrete. The basic principle of a ring test is that a concrete ring is cast around a steel core, which restrains the shrinkage of concrete, resulting in tensile stress developed in the concrete ring and compressive stress in the steel core. If the tensile stress is large enough, crack may be initiated. In this study, a circular ring is employed in current experiment, with its inner diameter is denoted as $a / 2$ (see Fig. 1)

In order to study the influence of concrete ring thickness on the shrinkage cracking potential, a variation of concrete wall thicknesses, i.e. $37.5 \mathrm{~mm}$ and $75 \mathrm{~mm}$ respectively, are introduced in the analysis of cracking mechanism. For the ring specimens with $35.5 \mathrm{~mm}$-thick wall, the inner diameter, $a$, equals to $300 \mathrm{~mm}$. Due to the size restriction of the environment chamber, a circular ring specimen with $a=250$ $\mathrm{mm}$ was tested for $75-\mathrm{mm}$ thick wall. The wall thickness of restraining steel cores and the height of the specimens are as 12.5 and $75 \mathrm{~mm}$, respectively. Four strain gauges were attached, each at one equidistant mid-height, on the inner circumferential surface of the central restraining steel ring and they were connected to a data acquisition system in a half-bridge configuration which is able to automatically record the circumferential strain of the inner surface of the restraining steel ring continuously. Following ASTM C1581/C1581M-09a protocol, the top and bottom surfaces of ring specimens were sealed using two layers of aluminum tape and drying was only allowed through the outer circumferential surface of the concrete rings. The strain gauges were then connected to the data acquisition system, and the instrumented ring specimens were finally moved into an environmental chamber after first day curing for drying under the temperature $23^{\circ} \mathrm{C}$ and $\mathrm{RH} 50 \%$ till the first crack occurred.

\section{NUMERICAL ANALYSIS OF STRESS DEVELOPMENT IN CONCRETE RINGS}

Finite element analyses were carried out using ANSYS code to simulate stress development with age in a series of concrete ring specimens under restrained shrinkage. It should be noted thatANSYS code does not directly support the shrinkage loading and there is no direct entry for shrinkage being included as a material property of concrete either as most engineering materials do not possess shrinkage as concrete does. Therefore, as an alternative method, shrinkage effect of concrete was represented by a fictitious temperature field applied on concrete ring specimens in numerical analyses in this study.

\section{A. Fictitious Temperature Field}

To reflect the same effect with dying shrinkage, it is essential to derivate a reasonable fictitious temperature filed in numerical analysis. Since the relationship between A/V ratio and shrinkage strain at different ages has been obtained 
for prisms in free shrinkage test (see Fig. 2), the relationship of $\mathrm{A} / \mathrm{V}$ ratio and fictitious temperature filed can be established if regarding as the shrinkage is caused by fictitious temperature. In addition, there is an assumption adopted in this study in numerical analyses, which is free shrinkage being the same for specimens with the same $\mathrm{A} / \mathrm{V}$ ratio even with different geometries, i.e., there will be the same fictitious temperature field acting on the specimens with the same $\mathrm{A} / \mathrm{V}$ ratio but maybe different geometries.

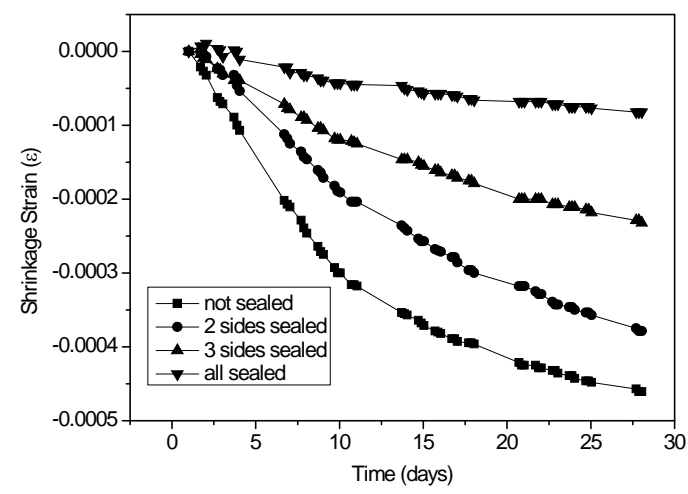

Fig. 2. Time dependent free shrinkage strain obtained from free shrinkage test

In case of a $37.5 \mathrm{~mm}$-thick ring, concrete shrinkage can be considered as being uniform across the wall[5-8] and the uniform temperature filed is applied to concrete by setting the same temperature drop in whole volume of concrete. The fictitious temperature drops at different ages canbe calculated by deriving the relationship between the measured shrinkage strain and the coefficient of linear expansion of concrete, i.e. $10 \times 10^{-6} /{ }^{\circ} \mathrm{C}$. In case of a $75 \mathrm{~mm}$-thick ring, the influence of moisture gradients across the thickness direction becomes more and more significant and cannot be neglected [3]. It is believed that the assumption, i.e. shrinkage strain and the resulted stress are uniform across the ring wall, for thin concrete rings is not appropriate for thick concrete rings [2]. Therefore, in this study, the fictitious temperature field acting on thick ring is consisted of two temperature drops, which are applied on sealed and exposed surfaces of ring specimen, respectively. Meanwhile, a linear gradient of temperature drop is applied across the ring wall to take into account the moisture gradient across thick concrete ring wall.

\section{B. Finite Element Analysis}

Finite element analyses were carried out to study the stress development in concrete rings subject to restrained shrinkage. The concrete ring specimens investigated in this study all had a depth of $75 \mathrm{~mm}$ with the inner steel ring having a wall thickness of $12.5 \mathrm{~mm}$. To investigate the effect of concrete wall thickness, two concrete wall thicknesses i.e., $37.5 \mathrm{~mm}$ and $75 \mathrm{~mm}$, were examined.

Three-dimension 20-node solid elements were used for the simulation of concrete and steel. In order to eliminate the effect of friction between concrete and steel, the outer circumferential surface of the steel ring, which contacts the inner circumferential surface of concrete ring, was suggested to be coated with a release agent by AASHTO PP34-99 and ASTM C1581/C1581M-09a and such measures was also taken in this study when preparing ring tests. Accordingly, in numerical analyses, contact element with zero friction between the contact pair was utilized to simulate this in conducting concrete ring tests in practice. Typical FE meshis shown in Fig. 3, in which the inner purple elements and outer blue element represented steel and concrete, respectively.

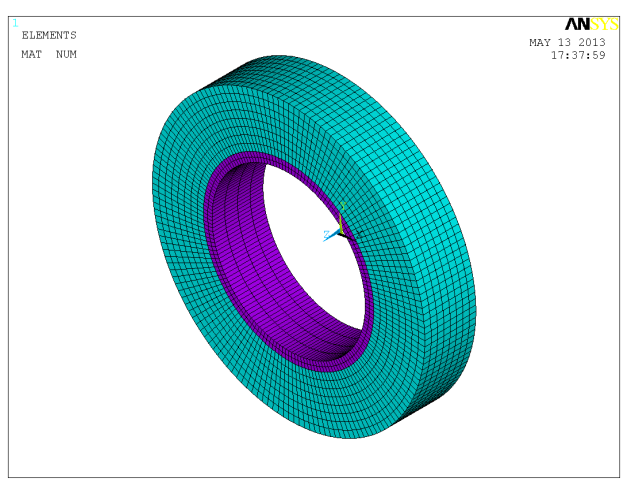

Fig. 3.Typical FE mesh for simulating thick ring in restrained shrinkage test

As mentioned previously, in numerical analyses, shrinkage was not a directly input as a material property of concrete. Rather, shrinkage effect was replaced by a fictitious temperature field applying on ring specimens. For thin ring specimens with $37.5 \mathrm{~mm}$-thick wall, a uniform temperature field with zero gradient across the thickness of concrete ring wall was used. For thick ring specimens with 75 mm-thick wall, considering the effect of humidity gradient across the wall, different fictitious temperature drops with the linear gradient were applied on the sealed and exposed concrete surfaces, respectively. Taking these parameters into finite element analysis, the time dependent circumferential stress in concrete rings was able to be obtained. The maximum circumferential tensile stress was taken in a cross section at the middle of a concrete ring specimen. When the maximum circumferential tensile stress becomes greater than the splitting tensile strength of concrete at certain age, crack will initiate in the ring specimen at that age.

\section{RESUltS AND DisCUSSION}

\section{A. Cracking Age}

To verify the numerical approach developed in this study, cracking ages of ring specimens with $37.5 \mathrm{~mm}$ and $75 \mathrm{~mm}$ concrete thicknesseswere predicted using the numerical model and were compared with those obtained from experiment. The circumferential stress was selected along a plane perpendicular to the depth direction at mid-height in ring specimen to obtain the stress values that were reported. When the maximal circumferential tensile stress developed in concrete ring reaches the tensile strength of concrete, crack will initiates and the corresponding timeis the cracking age. For $37.5 \mathrm{~mm}$-thick concrete ring, the cracking ages obtained 
from numerical analyses and experiment are 18 and 15 days. For $75 \mathrm{~mm}$-thick concrete ring, their ages are 18 and 19 daysfrom experiment and simulation, respectively.It can be seen that the numerical and experimental results of cracking age agreed reasonably well.

\section{B. Cracking Position}

For a standard ring test, crack may initiate at a random position of inner or outer edges due to the equal stress distributionalong its circumference. While, the geometry of ring specimen may influence the crack position, i.e. initiate at the inner or outer circumferential surfaces. As the outcomes of this analysis, the circumferential tensile stress contour from numerical analysis, when crack initiates, is presented in Fig. 4.

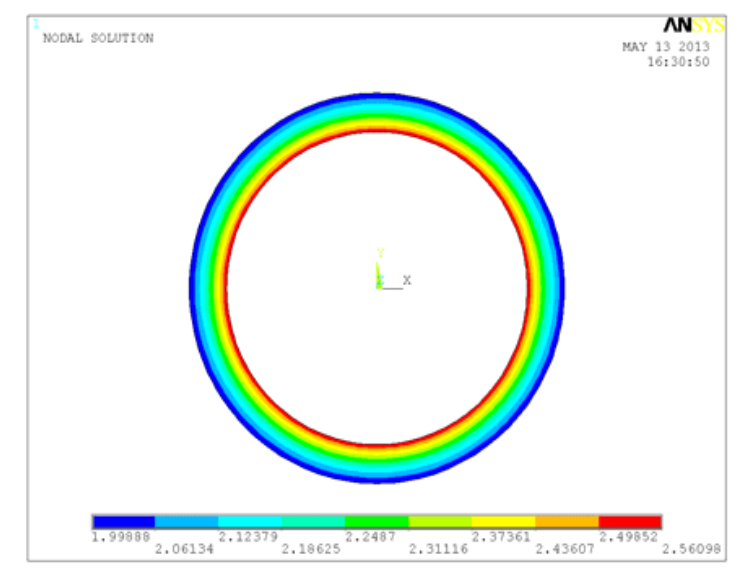

(a) $37.5 \mathrm{~mm}$-thick concrete wall

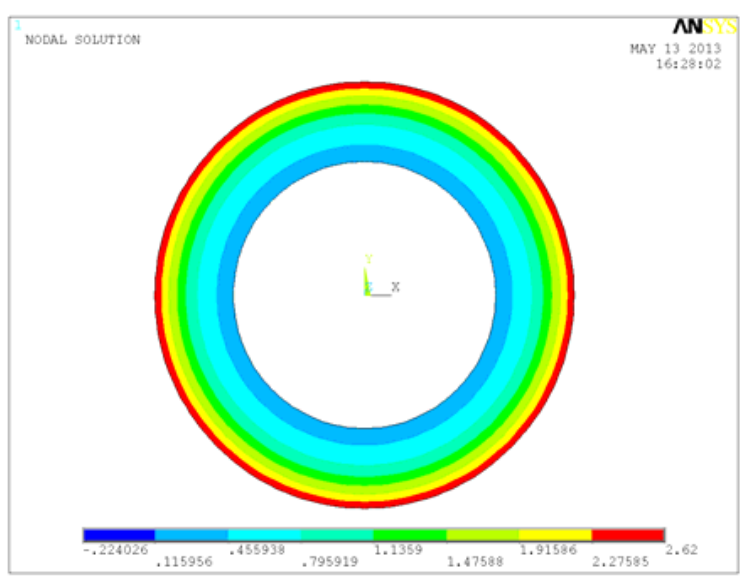

(b) $75 \mathrm{~mm}$-thick concrete wall

Fig. 4. Circumferential stress contour in ring specimens at the age of cracking initiation

It can be seen from Fig. 4(a) that the maximum circumferential tensile stress occurred at the inner circumference in $37.5 \mathrm{~mm}$-thick ring specimen, which indicates that crack initiated from the inner circumferential surface and propagates to outer edge of thin rings. But thing is different for case when concrete wall thickness increases from $37.5 \mathrm{~mm}$ to $75 \mathrm{~mm}$. Based on the circumferential stress contour presented in Fig. 4(b), the maximum circumferential tensile stress occurred at the outer circumference in 75 mm-thick ring specimen, which indicates that crack initiated from the outer circumferential surface and propagates to inner edge of thick rings. Therefore, it is concrete wall thickness that influences the crack initial position and propagation direction in restrained shrinkage ring test subject to outer circumference drying.
Meanwhile, due to the introduction of assumption of uniform across the ring wall in thin ring, the circumferential stress gradient is small, which thecircumferential tensile stresses at inner and outer circumference are $2.56 \mathrm{MPa}$ and 2.0 $\mathrm{MPa}$, respectively. While, for the thick ring specimen, because the moisture gradient is taken into account resulting from thick concrete wall, the gradient of circumferential stress increases obviously. Even the compressive stress occurs along inner circumference in $75 \mathrm{~mm}$-thick ring specimen, which the value is $0.224 \mathrm{MPa}$.

\section{CONCLUSION}

Experiment [4] has verified that, in the case of the restrained thick ring drying from the outer circumference, the crack initiates at the outer circumferenceand propagated towards the inner edge. While, although the assumption of crack initiation at the inner circumference was adopted by many researchers in the analysis of thin ring, it has not been tested and verified by experiment. Therefore, further research is needed.

\section{REFERENCES}

[1] A. B. Hossain and J. Weiss, “Assessing residual stress development and stress relaxation in restrained concrete ring specimens."Cement Concrete Comp, vol. 26, pp. 531-540, 2004.

[2] J. H. Moon and J. Weiss, "Estimating residual stress in the restrained ring test under circumferential dying," Cement Concrete Comp, vol. 28, pp. 486-496, 2006.

[3] J.Weiss, "Prediction of early-age shrinkage cracking in concrete," Ph.D. dissertation, Northwestern University, USA, 1999.

[4] A. B. Hossain and J.Weiss,"The role of specimen geometry and boundary conditions on stress development and cracking in the restrained ring test," Cement Concrete Res, vol. 36, pp. 189-199, 2006.

[5] S. P. Shah, C. Ouyang, S. Marikunte, W. Yang, and E. B. Giraudon,"A method to predict shrinkage cracking of concrete,"ACI Mater J, vol. 95, pp, 339-346, 1998.

[6] J. H. Moon, F.Rajabipour, B. Pease, and J. Weiss,"Quantifying the influence of specimen geometry on the results of the restrained ring test,"Journal of ASTM international,vol. 3, pp.1-14, 2006.

[7] K. Kovler, J. Sikuler, and A. Bentur,"Restrained shrinkage tests of fiber reinforced concrete ring specimens: effcts of core thermal expansion,"ACI Mater J, vol. 26, pp. 231-237, 1993.

[8] H. R. Shah and J. Weiss, "Quatifying shringkage cracking in fiber reinforced concrete using the ring test,"Mater Struct, vol. 39, pp. 887-899, 2006.

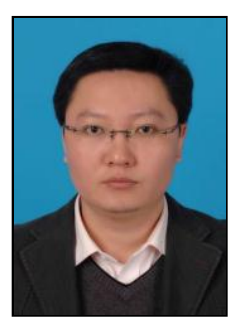

W. Dong was born in Liaoning Province, China, $6^{\text {th }}$ October, 1978. He received his bachelor degree in civil engineering from Dalian University of Technology, Dalian, China, in September 2001. He got his PhD. on Civil Engineering, from Dalian University of Technology, Dalian, China, April, 2008 His research field is concrete fracture mechanics.

$\mathrm{He}$ is a lecturer at Department of Civil Engineering, Dalian University of Technology. He joined Dalian University of Technology in April 2010. Before that, he conducted post-doctoral research at Dalian University of Technology from April 2008 to April 2010. He worked as a Research Fellow at School of Engineering and Design, Brunel University, UK from March 2012 to March 2013.

Dr. Dong a National First-class Registrations Structural Engineer of China. 


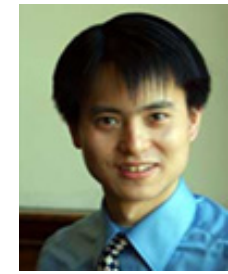

X.M. Zhou was born in Hubei province, China, $18^{\text {th }}$ November, 1975. In April 2005, he got his doctor degreeof Philosophy in Civil Engineering, Hong Kong University of Science and Technology,.

In July 1997, Dr. Zhou received bachelor degree of Engineering in Civil Engineering, Tongji University, Shanghai, China.

He also joined Brunel in October 2008 and asa Senior Lecturer in Civil Engineering at School of Engineering and Design, Brunel University. Before that, he was a Lecturer then Senior Lecturer in Structural Engineering at University of Greenwich from January 2007. Now, he has already conducted his post-doctoral research at Hong Kong University of Science and Technology and Hong Kong Polytechnic University. He also received his $\mathrm{PhD}$ in Civil Engineering from Hong Kong University of Science and Technology. Two degrees held by Dr. Zhou: BEng in Civil Engineering and MEng (Res) in Structural Engineering, both from Tongji University, Shanghai, China.

Currently, Dr. Zhou is the Scientific Manager of a European Commission 7th Framework Programme funded cooperation project, FIBCEM, with the value of $€ 3.8$ million delivered by a consortium with 10 partners from $5 \mathrm{EU}$ member state countries. He is the PI of an EPSRC project on developing a new method for assessing cracking potential of concrete and other cement-based materials, and involves in other national and international collaborative research projects.

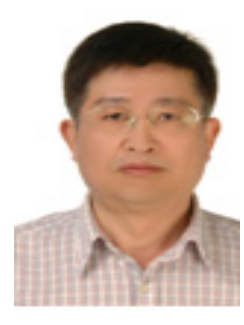

Z. M. Wuwas bron in Zhejiang Province, China, November, 1963. He received bachelor degree in engineering (Combustion Engine) from Dalian University of Technology, Dalian, China. 1986.

In 1989, he got his bachelor degree on Experimental Mechanics, Dalian University of Technology, Dalian, China.

And in 1993, he received another bachelor degree on Civil Engineering, Dalian University of Technology, Dalian, China.Now, He is a Professor at Department of Civil Engineering, Dalian University of Technology. Before that, he conducted post-doctoral research at Dalian University of Technology from 1993 to 1995 . From 2002 to 2003, he was a Visiting Scholar at Leipzig University of Applied Sciences, Germany. He also as a Senior Visiting Scholar at City University of Hong Kong in 2007. 